\title{
Uma "magnífica presa": representações visuais de Marilyn Monroe
}

\begin{abstract}
Annateresa Fabris ${ }^{1}$
RESUMO: As representações visuais de Marilyn Monroe pautam-se por duas estratégias fundamentais: a construção do mito por parte de fotógrafos e a configuração de uma memória crítica proposta pelos artistas plásticos. Desde De Kooning, a imagem da atriz torna-se uma presença constante no campo das artes plásticas. Numa demonstração da persistência de um ícone mítico, essa imagem abarca tanto a geração associada à pop art quanto artistas contemporâneos.

PALAVRAS-CHAVE: Marilyn Monroe. Mito. Fotografia. Artes Visuais.

ABSTRACT: Visual representations of Marilyn Monroe follow two main strategies: the construction of the myth (photographers) and the constitution of a critical memory (visual artists). Since de Kooning the image of the star is a constant presence in visual arts. As a proof of the permanence of a mythical icon such image includes the pop generation and contemporary artists.

KEY-WORDS: Marilyn Monroe. Myth. Photography. Visual arts.
\end{abstract}

Duas exposições realizadas em São Paulo em 2012 - Quero ser Marilyn Monroe! (Cinemateca Brasileira, de $\mathrm{O} 4$ de março a $1^{\circ}$ de abril) e A sedução de Marilyn Monroe (Museu Afro Brasil, de 08 de agosto a 07 de outubro) - servirão de ponto de partida para uma análise da construção da imagem pública da atriz e para rememorar como esta se tornou uma presença constante no imaginário contemporâneo, na qualidade de emblema de uma sensualidade que parecia não conhecer fronteiras.

Confirmando a ideia de Edgar Morin de que no universo cinematográfico "tudo parte da foto para voltar à foto"2, uma boa parcela das duas mostras era constituída por imagens fotográficas de Monroe que permitem acompanhar sua
1. Docente aposentada da Escola de Comunicação e Artes da USP. E-mail: <neapolis@ig.com.br>.

2. Cf. Edgar Morin (2007, p. $52,58)$. 
3. Registrado na língua inglesa em 1941, o termo "pin-up girl" designa imagens feitas principalmente para calendários a serem pendurados (pinned-up) na parede. A presença de imagens de pin-ups em veículos de comunicação de massa - cartões postais, revistas, jornais, cromolitografias - remonta, porém, à década de 1890 . A expressão "cheesecake photos", sinônimo de fotografias pin-up, tem seu uso documentado em 1934, mas é possível que circulasse desde 1914 na frase "better than cheesecake", aplicada a uma mulher atraente. Celebridades, sobretudo atrizes cinematográficas, integram o universo das pinup girls e suas imagens são veiculadas tanto por fotografias quanto por desenhos de autoria de artistas como Alberto Vargas, Gil Elvgren e George Petty, entre outros. A partir de 1946, Monroe trabalha para revistas como Laff, Peek, Glamorous Models, Cheesecake e U.S. Camera. Uma de suas parcerias mais famosas é com Earl Moran (19461950), que a retrata em trabalhos gráficos inspirados em fotografias de sua autoria; entre esses, podem ser lembrados Marilyn Monroe no paraíso (1948), Garota espanbola (1949) e Da próxima vez (1949). Cf. Pin-up, s.d.; Pin-up girl, s.d; The pinupfiles, s.d.

\footnotetext{
4. Composto de vinte $\mathrm{e}$ quatro tomadas, o ensaio é realizado em 27 de maio e tem a duração de duas horas. A aspirante a atriz, que assina o contrato como "Mona Monroe", recebe cinquenta dólares pelo trabalho. Cf. Golden dreams and New wrinkle. Marilyn Monroe nude, s.d. Algumas imagens do ensaio estão disponíveis em <www. marilyn-redvelvet-art.com/ pose10.html>.
}

transformação de pin-up em estrela, sobretudo na seleção apresentada na Cinemateca Brasileira. A pin-up, ou seja, a moça bonita que se converte em "matéria plástica para poses e metamorfoses sempre novas", que, no entanto, não the conferem uma identidade, é representada, de maneira emblemática, pelo ensaio Veludo vermelho, realizado em maio de 1949 por Tom Kelley4. A conotação erótica das fotografias, nas quais a jovem atriz, deitada nua numa manta de veludo vermelho, oferece à câmara "seu corpo, seus seios, seus quadris, sua carne" ${ }^{5}$, está na base do "caso do calendário", que vem à tona em 13 de março de 1952.

Uma das imagens de Kelley - Sonhos dourados -, que representava Monroe sentada de lado, com um dos braços dobrado atrás da cabeça, havia sido usada, sem a enunciação do nome da modelo, no calendário de uma firma de guindastes e transporte de motores, muito apreciado em barbearias, borracharias e postos de gasolina dos Estados Unidos. A revelação de seu nome, feita pela jornalista Aline Mosby, coloca a carreira de Monroe em risco, num momento em que ela estava se afirmando no universo hollywoodiano graças a filmes como $O$ segredo das joias (The asphalt jungle, 1950, John Huston), A malvada (All about Eve, 1950, Joseph L. Mankiewicz) e ao trabalho que estava realizando em $O$ inventor da mocidade (Monkey business, 1952, Howard Hawks)'b, no qual estreia o cabelo loiro platinado. A hipocrisia de Hollywood é revelada pela atitude da atriz, que confessa ter posado nua por questões de sobrevivência, ganhando, desse modo, a simpatia do público.

O "caso do calendário"7 acaba sendo determinante em sua carreira, pois ela é convidada a posar para a capa do primeiro número de Playboy, lançado em novembro de 1953, ano em que se destaca em filmes como Os homens preferem as loiras (Gentlemen prefer blondes, Howard Hawks) ${ }^{8}$, substituindo Betty Grable, e Como agarrar um milionário (How to marry a millionaire, Jean Negulesco). Além disso, nas páginas centrais da revista é publicada uma das fotografias do ensaio de Kelley, num gesto de desafio às leis "antiobscenidade" vigentes nos Estados Unidos na década de 1950. A imagem havia sido comprada por Hugh Hefner, diretor de Playboy, por um preço módico, de uma companhia de Chicago especializada na venda de calendários e cartazes de pin-ups, que havia renunciado a distribuir a fotografia da atriz nua pelo correio para não ser acusada de obscenidade. De acordo com Beatriz Preciado, a distribuição da fotografia colorida de Monroe nua pelos Estados Unidos foi

um fenômeno de massa sem precedentes. Hefner havia inventado a pornografia moderna não pelo uso de uma fotografia de um nu humano - algo recorrente nas publicações ilegais de revistas Nudies da época -, e sim pelo emprego da diagramação e da cor e pela transformação da imagem num encarte desdobrável que fazia da revista uma técnica portátil de "apoio estratégico" - para usar a expressão do exército americano - para a masturbação masculina. Na fotografia de Marilyn, o contraste na impressão das cores vermelho e carne e a ampliação da imagem em página dupla podiam ser considerados tão pornográficos quanto o próprio nu. (...) $\bigcirc$ que era pornográfico em Playboy não era a utilização de certas fotografias consideradas obscenas pelas instâncias governamentais de 
censura e vigilância do decoro, e sim o modo com que fazia irromper na esfera pública o que, até então, havia sido considerado privado. $\bigcirc$ pornograficamente moderno era a transformação de Marilyn numa informação visual mecanicamente reprodutível, capaz de suscitar afetos corporais ${ }^{9}$

A construção da imagem de Monroe pela fotografia

"Síntese da estrela e da pin-up"10, Monroe, depois do "caso do calendário", exibe um erotismo mais sutil, como comprovam sobretudo várias fotografias presentes na primeira exposição. Marilyn Monroe (1953), de Frank Powolny, fotógrafo da $20^{\text {th }}$ Century Fox, apresenta uma imagem brejeira e ao mesmo tempo cândida do símbolo sexual. Uma das imagens do ensaio Suéter vermelho (21 de fevereiro de 1955), de Milton Greene ${ }^{11}$, exibe-a numa pose íntima, em que o vermelho da peça de vestuário é o elemento determinante da composição, muito mais do que as pernas nuas. Marilyn preparando-se para sair (1955), de Ed Feingersh, encena um jogo sutilmente erótico e eivado de ironia, ao concentrar-se na interação entre a atriz e um frasco de Chanel n. 5, numa alusão à "lingerie" que ela dizia usar para dormir"2. No ensaio Uma noite com Marilyn (1961)13, Douglas Kirkland, fotógrafo da revista Look, constrói uma sequência sensual, a meio caminho entre erotismo e inocência, utilizando como cenário uma cama com lençóis de cetim.

Profissionais importantes não se furtam a fotografar a estrela. $\bigcirc$ inglês Cecil Beaton, famoso por seus retratos e pelas fotografias de moda, dedica-the um ensaio em 1956, no qual a representa em diversas poses, que dão a ver uma sensualidade natural, apesar da evidente encenação de cada tomada. O fotógrafo, que via em Monroe "uma figura com múltiplos paradoxos, ao mesmo tempo sirena tornada realidade e funâmbula, mulher fatal e criança ingênua, última encarnação de um retrato de Greuze ou de um semblante do século XVIII em um mundo muito contemporâneo", é autor da imagem preferida da atriz - deitada num sofá com um cravo sobre o peito, num gesto "ao mesmo tempo de proteção e de oferenda" 14 -, utilizada na correspondência com fãs e admiradores. Ernst Haas, associado à agência Magnum, flagra-a em 1960 numa pose sutilmente triste. No mesmo ano, o set de filmagem de Os desajustados (The misfits, 1961) é usado por Henri CartierBresson para apresentar Marilyn Monroe como uma figura melancólica e pensativa. Embora referidas à realização de John Huston, as considerações de Jonas Mekas sobre o rosto da atriz como "conteúdo, história e ideia do filme"15 aplicam-se às fotografias de Cartier-Bresson, autor de imagens densas que propõem uma visão diferente da estrela e de seu universo espiritual.

Um elemento comum às duas mostras paulistas foi não ter proporcionado ao público um encontro com fotografias da atriz anteriores à sua transformação em estrela. Faltaram imagens de Davis Conover, o fotógrafo que a descobriu e que divulgou sua imagem na edição de 26 de junho de 1945 da revista Yank, the
5. Cf. Edgar Morin (2007, p 52).

6. O ano de 1952 é particularmente favorável à jovem atriz, pois ela participa de mais três filmes: Só a mulher peca (Clash by night, Fritz Lang), Travessuras de casados (We're not married, Edmund Goulding) e Don't bother to knock (Roy Ward Baker). Além disso, será capa da revista Life no mês de abril.

7. Monroe, que havia começado a posar para calendários em 1947, verá a foto de Kelley ser usada para essa finalidade até 1955. Em 1953, duas imagens do ensaio são usadas em calendários: Sonbos dourados e A nova dobra (Monroe é representada de lado, esticando-se na manta vermelha). Em 1954, são feitos três calendários com Sonhos dourados: no primeiro, a modelo está vestida com uma roupa íntima preta; no segundo, aparece nua; no terceiro, uma cobertura transparente regulável proporcionava as duas possibilidades de visualização. Em 1955, circula uma variante de Sonhos dourados, com a modelo usando uma vestimenta sumária. Nesse mesmo período, a atriz posa para outros calendários, às vezes seminua. Essas imagens estão disponíveis em <https://www.pinterest. $\mathrm{com} / . . . /$ marilyn-monroecalendars>

8. Uma imagem do filme será usada na série Divas (c. 2000), realizada pelo ilustrador brasileiro José Luiz Benício da Fonseca (Benício). Na série, Benício homenageia também Carmen Miranda, Jean Harlow, Audrey Hepburn, Rita Hayworth, Vivien Leigh e Ava Gardner, entre outras. A ilustração está disponível em $<$ www.benicioilustrador. com.br>. 
9. Cf. Beatriz Preciado (2010, p. 25-27). A expressão "apoio estratégico" fora cunhada pelo governo norte-americano para designar a distribuição de fotos de mulheres nuas durante as duas guerras mundiais para aliviar a tensão das tropas.

10. Cf. Edgar Morin (2007, p. 52).

11. O ensaio está disponível em $<$ https://www.facebook. com/media/set/?set=a...3 $>$.

12. A fotografia está disponível em <www. fulcrumgallery.com/EdFeingersh/Marilyn-MonroeChanel-no-5_660129.htm>.

13. O ensaio está disponível em <abcnews.go.com/blogs/entertainment/2012/11/ photographing-marilyn-lovemaking-with-the-lens>

14. Cf. Cecil Beaton apud Stanley Buchthal; Bernard Comment (2011, p. 260). A fotografia pode ser vista no site <www.themarilynmonroesite.com/ACecilBeatonPhotograph.htm>.

15. Cf. Jonas Mekas (2005, p. 246). As fotografias podem ser vistas no site $<$ https://www.magnumphotos. com/Catalogue/Henri-Cartier-Bresson/1960/UNITED-STATES-Nevada-Film-The-Misfits>.

16. Fotografias de Bruno Bernard disponíveis em $<$ https://www.pinterest.com/ debraannpayne/monroe-bruno-bernard>.

17. Fotografias de André de Dienes disponíveis em $<$ thisismarilyn.com/marilyn-monroe-1946-by-andre-de-dienes-124460.photo>.

18. Álbum disponível em $<$ www.josephkleveneltd. com/NewSite/WarholMarilynSet.htm\#.VQNd69LF_ ps>.
Army Weekly, num ensaio dedicado a mulheres que trabalhavam na indústria bélica (Figura 1); de Bruno Bernard ${ }^{16}$, com quem a atriz começou a colaborar em 1945 na produção de fotografias pin-ups; e de André de Dienes ${ }^{17}$, responsável por uma divulgação bastante ampla de fotografias da pin-up (1945-1946) e da atriz (1952-1953) em revistas norte-americanas e internacionais.

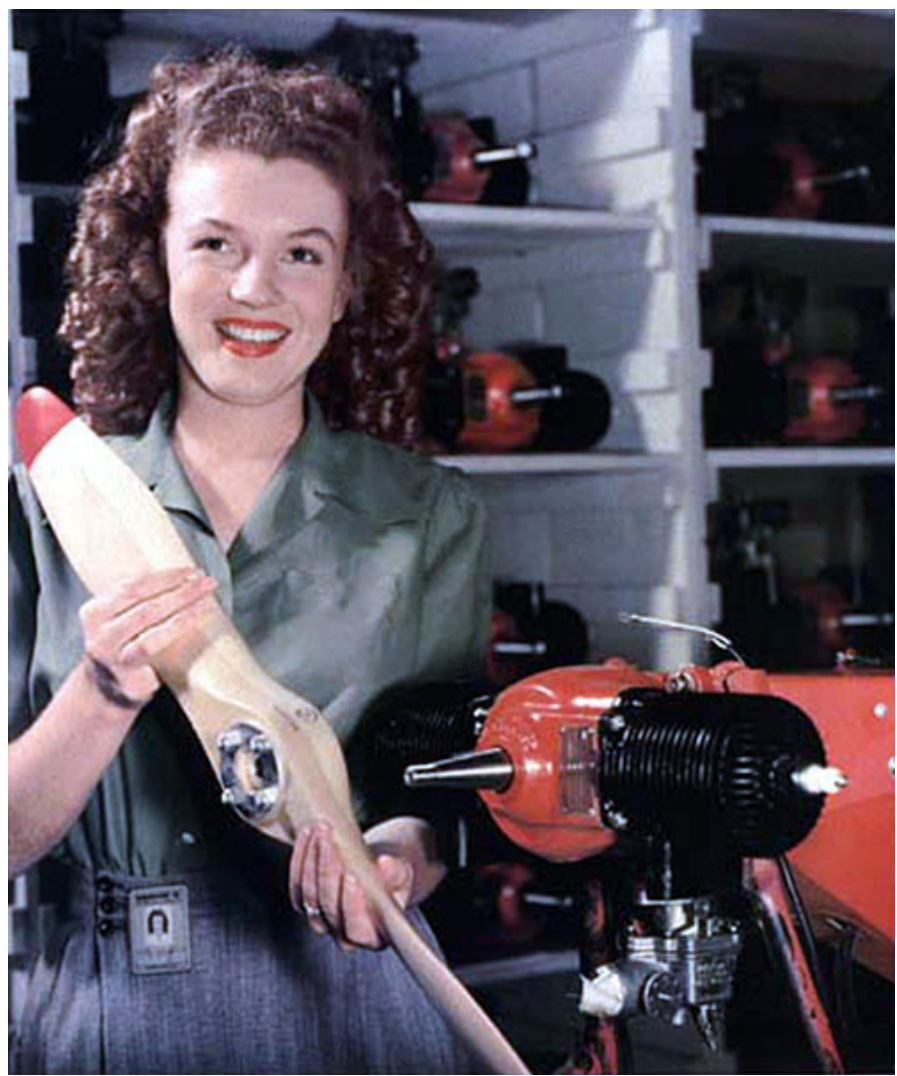

Figura 1 - Davis Conover. Senhora Norma Jean Dougherty, 1945. Imagem em domínio público.

Monroe vista por artistas visuais: exemplos presentes nas duas mostras paulistas

Outro eixo das duas mostras, constituído basicamente por obras de artistas plásticos associados à pop art e às novas figurações, ou de expoentes de gerações mais recentes, era uma demonstração parcial do impacto provocado pela figura da atriz sobre a imaginação masculina desde sua conversão em diva. A imagem de Monroe, de que Andy Warhol se apropriou em 1962 e que se tornou matriz de diferentes trabalhos, não foi deixada de lado nas duas curadorias. Enquanto 4 Marilyns, extraída do álbum Marilyn (1967)18, esteve presente na primeira exposição, Emanoel Araújo, curador da segunda, optou por serigrafias maiores da mesma imagem. No álbum, o rosto da atriz é submetido a dez 
tratamentos cromáticos extravagantes que corroem o caráter indicial da fotografia que serviu de ponto de partida, transformando-o numa caricatura ou numa máscara bizarra. Se a cosmética de Warhol afirma e nega ao mesmo tempo a ideia de glamour associada a ela, bem mais radical é o conjunto de dezessete litografias concebido por Richard Lindner em 1970, Marilyn esteve aqui, no qual se assiste a uma operação de desmontagem crítica do grande ícone da sensualidade feminina.

que chama a atenção na geração pop é a persistência do mito da estrela no imaginário de artistas como Eduardo Paolozzi (Dois heróis, 1986); Peter Blake (M para Marilyn Monroe, 1991 ); Erró, que the dedica duas colagens em 2001 ; Robert Indiana, autor de Raios solares Marilyn (2001); Mel Ramos que, em 2002, insere imagens da atriz na retomada da série Peek-a-boo concebida em 1964 19; Mimmo Rotella, representado pela décollage realizada em 2003, Magnifica preda ${ }^{20}$. Esse fenômeno ocorre também no Brasil, como comprovam Sem título (s.d.), de Maurício Nogueira Lima; Sem título (1997), de Newton Mesquita; Marilyn (2008), de Ivald Granato; Marilyn (2012), em que Nelson Leirner reafirma uma visão sensual da atriz.

Nesse prolongamento da imagem mítica de Monroe, não pode deixar de ser destacada a volta de Ramos e Rotella a uma iconografia enraizada na década de 1960. $\bigcirc$ artista norte-americano, que já havia se apropriado da imagem da atriz nesse período, insere-a no âmbito de "Peek-a-boo", reiterando a visão de uma mulher ao mesmo tempo desinibida e inocente. Inspirada num cartãopostal da década de 1940, a série deriva seu nome de uma brincadeira em que um adulto aparece e se esconde repetidas vezes para divertir um bebê. Os quadros voyeurísticos de Ramos, que representam nus femininos vistos através de gigantescos buracos de fechadura, ao mesmo tempo em que não deixam muito espaço para a imaginação do observador, destacam-se por um aspecto lúdico, que coloca uma nota irônica na composição.

Rotella, por sua vez, realizou Magnifica preda ${ }^{21}$ a partir do cartaz italiano do filme $O$ rio das almas perdidas (River of no return, 1954, OHo Preminger), que marcou a transformação de Monroe em "good-bad-girl", ou seja, numa mulher sedutora, mas bondosa, depois da explosão erótica de Torrentes de paixão (Niagara, 1953, Henry Hathaway), no qual havia encarnado, nos dizeres de Morin, o personagem da "vamp úmida"22. $\bigcirc$ artista italiano já havia usado a técnica da décollage - uma variação da colagem dadaísta, a meio caminho entre a pintura gestual e a pop art - em Marilyn (1962). Nessa, os efeitos "pictóricos" decorrentes do gesto de rasgar um cartaz eram acompanhados pela preservação de uma imagem quase integral, que adquiria um efeito de estranhamento, em virtude do contexto em que se encontrava inserida ${ }^{23}$. Como escreve Angela Vettese, a operação realizada pelo artista não deve ser vista como um comentário ao filme; trata-se, antes, de uma resposta ao cartaz e aos temas que este suscita. Por isso, ele deve permanecer integral, pelo menos em termos de proporções, para que seja possível perceber como era antes da intervenção do artista. $\bigcirc$ conjunto de rasgos
19. Obra disponível em $<$ www.retrogasm.ne/home/ mel-ramos-peek-a-boo-marilyn-monroe>.

20. Mimmo Rotella já havia realizado em 1963 a décollage Marilyn. La magnifica preda Cinemascope.

21. Uma das obras da série pode ser vista disponível em $<$ www.pisacanearte.it/index.phps/mimmo-rotella-1287.html>.

22. Cf. Edgar Morin (2007, p. 31-32).

23. A partir de 1962, Mimmo Rotella dedica várias obras à atriz. Dentre elas podem ser lembradas: The hot Marilyn (1962), Marilyn maquiada (1962), Marilyn. A mulber mais bela (1962), Marilyn - Mito de uma época (1963), Marilyn mito (1963-1979), Marilyn Niagara (19631980), Amiamoci (19631988), Marilyn e suas damas (1963-1989), The misfits (1963-1989), Música (Marilyn, 1965-1970), Cinemascope 2 (1965-1982), La dernière Marilyn (1966), Marilyn on stage (1990), Marilyn na praia (1998), La preda (1998), Marilyn apaixonada (1998) e Monroe (1998). Algumas dessas obras podem ser vistas no site <www.art. c o m / g a 11 e r y / i d a76191-b241421/mimmorotella-marilyn-monroe-artposter.htm>. 
24. Cf. Angela Vettese (2002, p. 18-19).

25. A sedução de Marilyn Monroe dá a ver muito claramente a dimensão de ícones de massa adquirida pelas representações visuais da atriz graças a diferentes objetos que se valem de sua imagem para alavancar o consumo: camisetas, caixas, capas de caderno, relógios, esculturas kitsch, maletas, guardanapos de papel, descansos para copos, bolsas, bonecas, embalagens de pipoca, chapéus de festa... Nesse conjunto heterogêneo, merecem ser lembrados os copos descartáveis de Coca-Cola com os dizeres "XXIII Bienal de São Paulo", que acabam por corroborar a imagem da atriz como um item de consumo entre outros, pouco importando o contexto em que esteja inserido. parece propor-se como um retrato da impressão que o cartaz provoca. A figuração não desaparece, (...) mas fica excluída toda necessidade de narração concreta. Rotella apropria-se do cartaz enquanto mensagem unitária porque só esse respeito inicial the permite criar um verdadeiro duplo circuito entre figuração e abstração, impressão e manualidade, arte popular e arte experimental24.

Warhol e sua imagem de 1962 estão na base de algumas obras contemporâneas selecionadas para as duas mostras. Enquanto em Marilyn Monroe - Picture of diamonds (2004), Vik Muniz propõe um tratamento "rico" da releitura de Warhol, Heidi Popovic (pseudônimo de Christian Polzer) apresenta uma versão macabra dessa mesma imagem. Marilyn contemporânea (2008), fruto da associação entre fotografia e morte, converte em quatro caveiras o rosto celebrizado de diversas maneiras desde 1962. No caso brasileiro, o diálogo com a obra de Warhol é atestado por Marilyn in the skies with diamonds (s.d.), de Caíto, marcada pela fragmentação, e pelas apropriações de Mesquita e Granato. Se essas operações demonstram o fascínio por uma imagem transformada em representação icônica da atriz, poder-se-ia também indagar se os diversos gestos de apropriação não seriam testemunhas do impacto de Warhol no imaginário dos artistas contemporâneos, mais do que uma homenagem à memória de Monroe.

Outras obras contemporâneas destacaram-se nas mostras. Marilyn II e Marilyn III (2003), de Werner Berges, expõem o elo indissolúvel entre a construção do mito e o consumo de massa ${ }^{25}$ ao configurar a imagem da atriz com códigos de barras coloridos. Marilyn e Kennedy (2008), de Kim Dong-Yoo, rememora o romance entre a diva e o presidente dos Estados Unidos graças ao uso de pixels. Com estes, o artista constrói a efígie de Kennedy a partir de pequenos rostos de Monroe, usando o processo inverso na configuração da imagem desta. $\bigcirc$ resultado é estimulante, pois provoca um estranhamento momentâneo no observador, confrontado com um princípio de metamorfose.

Visões críticas da atriz e da aura que a cerca estão também na base de diversas obras selecionadas por Emanoel Araújo, a começar por MM (2012), com a qual Cláudio Tozzi reporta o mito à dimensão de uma logomarca geometrizada. Marilyn in the skies with diamonds (s.d.), de Caíto, dialoga com as representações do artista português José de Guimarães, igualmente devedoras da imagem seminal de Warhol e concentradas na definição de um contorno azul ou amarelo, em cujo interior se destaca o vermelho dos lábios. $\bigcirc$ uso da sinédoque caracteriza também Marilyn multidimensional 2 (2012), de Futoshi Oshizawa, em que o sorriso é o eixo central da composição. Repetida duas vezes, a fotografia é acompanhada pelos versos iniciais de uma canção interpretada pela atriz em Quanto mais quente melhor (Some like it hot, 1959, Billy Wilder) - "I wanna be loved by you just you and nobody else but you" ["Quero ser amada por você, só você/E ninguém além de você"] -, que acaba por conferir um significado absolutamente diferente ao que pareceria uma homenagem à sensualidade da atriz (Figura 2). 


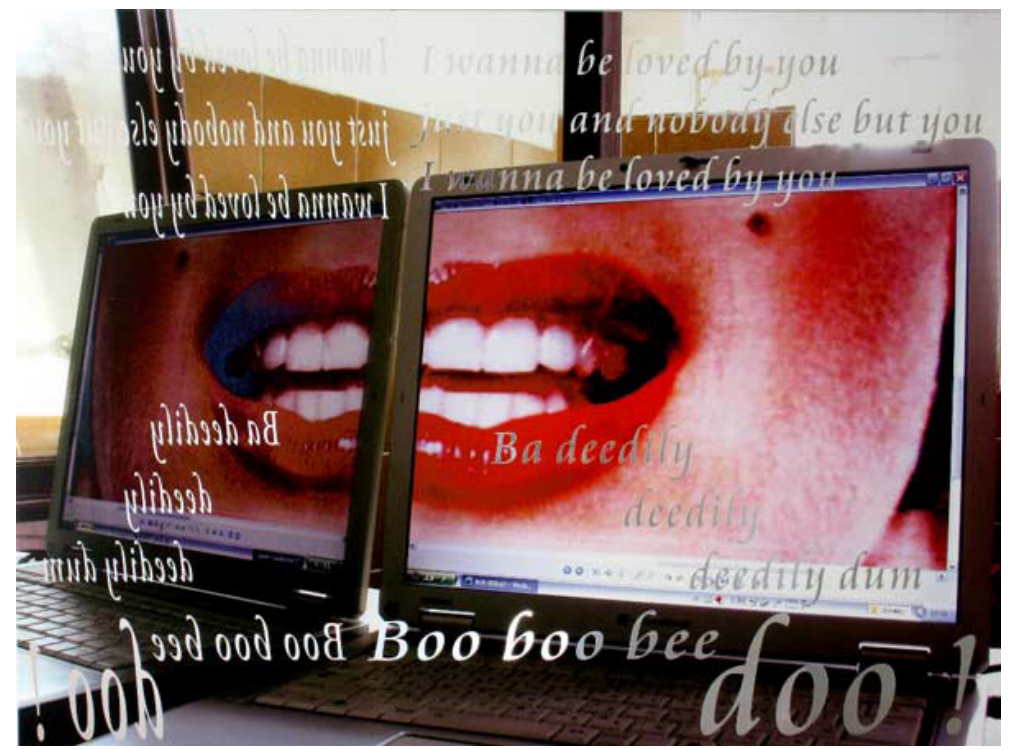

Figura 2 - Futoshi Oshizawa. Marilyn multidimensional 2, 2012. Divulgação Museu Afro Brasil.

A desconstrução do mito sensual está também presente em Sem título (2012), de Gláucia Amaral. A artista recobriu um manequim de vitrine com uma foto de Monroe vestindo um suéter de mangas curtas e colocou perto dos pés um frasco de Chanel n. 5. A aparente afirmação da figura sensual é contrastada por uma inscrição no chão, na qual a atriz se interroga sobre o poder de sedução presente num item corriqueiro do vestuário feminino ("Não sei por que os rapazes ficam tão assanhados por causa das garotas de suéter. Se tirarem o suéter que é que elas têm?"). Outro tipo de questionamento a respeito da figura pública da atriz permeia alguns trabalhos de Domenico Salas, em que um rosto pintado recebe diversas intervenções nos olhos: nuvens em Clouds Marilyn (2011); a retomada da fotografia Lágrimas (1932), de Man Ray, em Man Rayrilyn (201 1)26; a reprodução do quadro Ofélia (1851-1852), do pintor pré-rafaelita John Everett Millais, em Ophelia Marilyn (2011). A interrogação sobre o significado de uma existência e a evocação do fim trágico da atriz, que estão na base das obras de Salas, servem também de parâmetro para um trabalho aparentemente críptico, Cursum perficio (2012), de Roberto Okinaka, cuja tradução, "Fim de percurso", aparece em letras vermelhas no interior de uma caixa. Uma etiqueta explica que ela estava gravada na soleira da última casa de Marilyn Monroe, ocupada quatro meses antes de sua morte.

A obra de maior impacto na seleção de Araújo é a instalação Amour et panique (s.d.), da artista espanhola Maribel Domènech. Com o auxílio de fios e lâmpadas Led vermelhas, Domènech grafa o título da obra numa parede e reproduz o vestido sensual usado pela atriz na festa de aniversário de Kennedy, celebrada no Madison Square Garden (Nova York), em maio de 1962. 0

26. Domenico Salas apropria-se de outra imagem de Man Ray, o retrato da Marquesa Casati (1922), para configurar Marilyn Man Ray, cujo traço distintivo é a repetição dos olhos. 
27. Ensaio disponível em <www.artnet.com/artists/ bert-stern>.

28. Ver Hans-Michael Koetzle (2005, p. 263).

29. Obra disponível em $<$ www.tate.org.uk/ artworks/hamilton-mymarilyn-p04251>.

30. O fotógrafo Stuart Lester Rankin fez uma homenagem bem-humorada à famosa cena do vestido esvoaçante de $O$ pecado mora ao lado. Em Alex McFaydan (s.d.), apresenta um homem robusto, usando um kilt levantado pelo vento, que exibe sorrindo a própria genitália.

31. Ver Klaus Honnef (2004, p. 38).

32. Cf. Richard Hamilton apud Van Deren Coke (1972, p. 249). ambiente é composto ainda por três fotografias - da atriz, do presidente e de Clark Gable -, pela projeção de imagens e de obras inspiradas na figura de Monroe e por um fundo musical em que esta interpreta Happy birthday Mister President e I wanna be loved by you, numa remissão emblemática a seu caso mais célebre e à sua constante busca de afeto.

Algumas imagens paradigmáticas

Ausente do recorte apresentado pela Artoma (Hamburgo) na primeira mostra, o ensaio realizado por Bert Stern em julho de 196227, que se tornou conhecido como "A última sessão de Marilyn", é, ao contrário, evocado na curadoria de Araújo por meio de diversas imagens. Durante três sessões a atriz posou para o fotógrafo oferecendo um leque de possibilidades visuais: sem maquiagem ou levemente maquiada; ensaiando jogos eróticos com um lenço transparente e com um colar; usando vestidos luxuosos e peles; com um sorriso nos lábios ou melancolicamente pensativa. A revista Vogue, que encomendara o trabalho, prefere publicar as fotografias em preto e branco na edição prevista para $\mathrm{O6}$ de agosto. A morte da atriz um dia antes transforma a celebração em obituário, pois a revista é obrigada a rever o título e o teor do artigo que acompanhava as imagens. Quanto às fotografias coloridas, dois terços delas não foram aprovados por Monroe, que assinalou com um X feito com um marcador as que não eram de seu agrado. Algumas delas ficaram seriamente comprometidas por um gesto mais violento: o uso de um grampo de cabelos diretamente nas transparências coloridas. A conclusão a que chega $O$ fotógrafo enlaça-se com o fim trágico da modelo: ela não tinha se limitado a riscar as imagens, uma vez que o gesto de recusa implicava o apagamento de si mesma ${ }^{28}$. Esse gesto, empregado pela atriz em diversas ocasiões, é explorado por Richard Hamilton em Minha Marilyn (1965)29. Hamilton, que havia utilizado um cartaz gigantesco com a figura de Monroe em $O$ pecado mora ao lado (The seven year itch, 1955, Billy Wilderl ${ }^{30}$ no exterior do pavilhão concebido em parceria com John McHale e John Voelcker para a exposição Isso é amanhã (1956), configura Minha Marilyn a partir de uma folha de provas contato, de autoria de George Barris. Publicadas na revista Town com anołações pessoais da atriz - que utilizava a palavra "good" para as fotografias que the agradavam, enquanto marcava com cruzes nervosas as que não desejava divulgar -, as imagens ajudam o artista a propor uma análise gráfica concisa dos mecanismos aos quais ela devia a própria fama ${ }^{31}$. Na "obliteração agressiva" feita pela atriz na própria imagem, Hamilton detecta dois movimentos: "uma implicação autodestrutiva que sua morte tornou ainda mais pungente" e "um narcisismo fortuito, pois a cruz negativa é também um símbolo infantil para o beijo. Minha Marilyn começa com os signos e elabora as possibilidades gráficas que estes sugerem" ${ }^{\prime 2}$.

Hamilton lança mão de um método preciso para construir a obra. Coladas diretamente na tela, as imagens recebem intervenções do artista - alteração de 
provas contato descartadas, imitação do gesto de recusa, refazimento pictórico de outras - que sobrepõe a própria marca às do fotógrafo e da atriz, de maneira a evidenciar os diversos níveis de intervenção possíveis numa fotografia. Com as intervenções manuais o artista deseja demostrar que o grau de perfeição buscado por Monroe dependia de diferentes manipulações capazes de reconciliá-la com a própria imagem. Hal Foster, para quem a atriz, ao agir como um "editor impiedoso" da própria aparência, demonstrava, por meio das marcas, "como desejava parecer, aparecer, ser", denominará essa atitude de "indicações editoriais"33.

As marcações feitas pela atriz nem sempre são levadas em conta por Hamilton. Uma imagem considerada "boa" por ela é submetida a uma transformação radical. Contra um céu dividido em dois campos cromáticos - púrpura e laranja - a imagem de Monroe destaca-se como um contorno vazio, em virtude da tinta branca que oblitera as feições do rosto e confere ao corpo uma dimensão fantasmática. Se o objeto erótico é posto em xeque nessa série de transformações, o que resta do mito hollywoodiano? Uma visão desapaixonada da relação entre o ser e a imagem, que converte a atriz num objeto de consumo entre tantos, não obstante o controle exercido por ela sobre suas representações públicas.

Essa visão é corroborada por um artigo de 1969, em que Lawrence Alloway remete a imagem de Marilyn Monroe a duas obras emblemáticas da relação da pop art com o sistema de comunicação do século XX. Enquanto Warhol usa uma imagem fotográfica repetida à maneira de provas contato e colorida com - cromatismo barato das reproduções de uma revista cinematográfica destinada ao público hispânico, Hamilton estabelece um contraponto entre a imagem mecanicamente produzida de uma bela mulher já morta e as anotações manuscritas que alteram a imagem de carne, numa demonstração de um dos mecanismos fundamentais da vertente: a inter-relação entre semelhança e dessemelhança ${ }^{34}$.

Antes de realizar a análise da representação plástica mais conhecida de Monroe, parece oportuno lembrar algumas obras que lhe foram dedicadas por outros artistas, uma vez que estas ajudam a aquilatar o significado de sua imagem para diversas gerações. Marilyn Monroe (1954) ${ }^{35}$, de Willem de Kooning, destacase por propor uma imagem "deserotizada" da modelo, apesar do destaque dado aos olhos, à boca vermelha e aos seios. A Marilyn do pintor holandês, que emerge de um fundo caótico de pinceladas esparsas, caracteriza-se por um desenho primitivo e rudimentar. Dele provém a percepção da atriz como uma boneca grotesca ou uma representação pré-histórica da fertilidade, em virtude da acentuação dos caracteres sexuais, notadamente os grandes seios.

À imagem disforme de De Kooning podem ser contrapostas visões mais realistas da atriz em obras realizadas também na década de 1950 por Ray Johnson e Peter Blake. Em Mão Marilyn Monroe (1958), Johnson apropria-se da fotografia de Powolny feita na época de Os homens preferem as loiras (1953) para propor um jogo com uma imagem inacessíve ${ }^{36}$. Cortadas em tiras, as fotografias da mão e da atriz são posteriormente reagrupadas e cobertas com areia e com uma tinta rosa carregada. $\bigcirc$ efeito de cortina ou de véu criado pelas tiras nada mais faz do
33. Cf. Hal Foster (2012, p. 55-57).

34. Ver Lawrence Alloway (2005, p. 242).

35. Obra disponível em $<$ https://www.neuberger. org/exhibitions.php ?view $=55>$.

36. Ver Marco Livingstone (2003, p. 293). Obra disponível em <www. rayjohnsonestate.com/art/ museum-and-privatecollections/works/10>. N.B. está reproduzida de pontacabeça. 
37. Obra disponível em <www.ccagalleries.com/ artists/peter-blake/girliedoor.html>.

38. Obra disponível em $<$ www.wikiart.org/en/peterphillips/for-men-onlystarring-mm-and-bb-1961>.

39. Román Gubern (1974, p. 239-240).

40. Obra disponível em <www.wikiart.org/en// a 11 a n-d - a r c a n g e 1 o / marilyn-1962>

41. Obra disponível em <www.moma.org/learn/ moma_learning/jamesrosenquist-marilynmonroe-i-1962>.

42. Obra disponível em $<$ https://thegenealogyof style.wordpress.com/ 2014/10/31/portraits-ofmarilyn-monroe/>. que acentuar a distância existente entre o ícone e a mão que pretende agarrá-lo, remetendo a pose sedutora ao universo imaterial da fantasia erótica. Esta encontrase também na base da obra de Blake, A porta das garotas (1959) ${ }^{37}$, na qual Monroe divide o espaço com fotografias de outras atrizes contemporâneas (Gina Lollobrigida, Kim Novak, Shirley McLaine, Elsa Martinelli), com imagens de estrelas do cinema silencioso e com cartões-postais sentimentais, todos igualmente determinantes na configuração de uma fantasia erótica que não estabelece distinções entre atualidade e anacronismo.

O voyeurismo implícito na atitude de Blake faz-se presente também em Só para homens, $M M$ e BB como estrelas (1961) ${ }^{38}$. Peter Phillips utiliza na obra fotografias reais (atrizes) e simuladas (sequência do peep show), definindo a composição por um desenho que engloba as diversas áreas no formato de um fliperama. A ideia de uma sexualidade comercializada é o traço de união entre os dois grupos de imagens. Monroe e Brigitte Bardot, cujas fotos foram extraídas de revistas ilustradas, são apresentadas como arquétipos sobrepostos à pessoa, como estilizações metonímicas do sexo ${ }^{39}$, em nada diferentes da anônima figura empenhada em satisfazer o voyeurismo de um espectador solitário no peep show.

Em 1962, as obras dedicadas a Monroe multiplicam-se, como uma resposta emocional à sua morte trágica. Em Marilyn ${ }^{40}$, Allan D'Arcangelo propõe uma visão desmistificadora do símbolo sexual. Destituída de feições e, logo, de personalidade, a atriz é representada como uma boneca de papel, cujo rosto deveria ser constituído a partir de recortes estereotipados da boca, do nariz e dos olhos. Marilyn Monroe ${ }^{41}$, de James Rosenquist, é um jogo perceptivo baseado na fragmentação e na possibilidade de reconstituição de uma imagem, cujos signos característicos - boca sorridente, nariz e olhos - não remetem necessariamente à efígie da atriz. Cabe ao espectador, confrontado com esse quebra-cabeça visual, acreditar (ou não) no ato de nomeação do artista, o qual ganha reforço no bloco de letras que formam um M. A décollage Marilyn Monroe ${ }^{42}$, de Wolf Vostell, é outro exemplo eloquente de uma visão crítica da imagem da atriz. Manipulando fontes diferenciadas - fotos publicitárias, capas de revistas, recortes de jornais -, que recobre com tinta, marca ou rasga, o artista alemão propõe uma contraleitura do significado original das imagens de que se apropria. Dispostas numa grade, as imagens deterioradas da atriz convocam várias possibilidades de leitura, podendo ser vistas como símbolos da efemeridade da fama, como objetos de vandalismo, como ícones descartáveis, sujeitos a um desgaste rápido nos muros da cidade e nas bancas de jornal.

No âmbito da pop art destacam-se outras obras dedicadas à atriz ao longo da década de 1960. A única loira do mundo (1963), de Pauline Boty, derivada de um fotograma de Quanto mais quente melhor, responde a um processo de identificação da artista com a figura da estrela, na qual detecta a porta-voz de uma sexualidade feminina consciente. Modelo de beleza, a atriz é representada como "uma miragem de glamour", que avança confiante em direção ao observador. Segundo Kalliopi Minioudaki, a crítica Sue Tate destaca agudamente a maneira com que Boty capta a sensualidade cinestética da fascinação que Monroe exercia 
sobre as mulheres: "a pincelada confere uma proximidade tátil, evocando o formato dos quadris, o movimento das borlas no vestido, o movimento das pernas" 43 . Dois anos mais tarde, o brasileiro Waldemar Cordeiro debruça-se sobre sua sensualidade com a obra Rebolando, composta por um garrafão cheio de água, apoiado sobre uma base que continha uma fotografia da atriz. A inscrição "agite neste sentido" era um convite à participação do espectador; ao realizar a ação, este assistiria a um movimento sinuoso de Monroe.

Em 1967, a figura da estrela é focalizada por Tom Wesselmann, George Segal e Rosalyn Drexler. Wesselmann radicaliza ainda mais o processo de fragmentação corporal, usado por Rosenquist em Marilyn Monroe I. Em Estudo para a boca de Marilyn, que reduz a atriz a uma única característica sensual, o artista aciona o mecanismo da "cisão sexual"44, ou seja, da representação da mulher a partir de atributos fragmentários, próprios da pornografia e do voyeurismo. Em Cartaz de cinema, Segal põe uma de suas estátuas diante de uma fotografia de Monroe, criando um duplo movimento no observador: distanciamento do modelo neutro e estático e sensação de familiaridade por seu aspecto corriqueiro e medíocre. Lançando mão do princípio fotográfico, o artista congela sua figura num gesto ordinário, conferindo-the uma única possibilidade: testemunhar a própria presença material ${ }^{45}$ no confronto com um arquétipo do desejo. Se a suspensão temporal é a principal característica da obra de Segal, Marilyn perseguida pela morte $^{46}$, de Drexler, baseia-se, ao contrário, num princípio dinâmico, ao mostrar a atriz sendo acossada por uma figura masculina. $\bigcirc$ clima de tensão que domina a cena é magnificado pelo espelhamento entre as duas figuras, que usam óculos escuros e trajam roupas de cores idênticas, e pelo halo vermelho que as cerca e as unifica, criando um efeito de recorte. Graças a esses recursos e aos tons conferidos aos rostos - cinza esverdeado (perseguidor) e cinza (atriz) -, Drexler transforma uma cena corriqueira (Monroe protegida pelo guarda-costas) numa representação dotada de uma angústia fria.

Representada também por Salvador Dalí, que lhe dedica uma releitura da obra primitiva de De Kooning (Marilyn Monroe, 1972)47, a estrela é lembrada de maneira peculiar por Yasumasa Morimura e Mark Lancaster. Conhecido pela apropriação de obras de arte e de fotografias de celebridades, recriadas por meio de autorretratos en travesti, Morimura dedica diversas obras à atriz, nas quais a homenagem atinge, não raro, tons sarcásticos e grotescos. É o que demonstra Autorretrato (Atriz). D'après Marilyn vermelha (1996), resultado da apropriação da pose n. 1 do ensaio de Kelley. $\bigcirc$ artista imita a pose sensual de Monroe - de boca entreaberta, com um braço cruzado atrás da cabeça, ocultando a genitália, mas evidenciando os seios -, porém injeta uma nota estranha na composição. Nela tudo é evidentemente falso: o rosto muito branco, a evocar as máscaras do teatro kabuki; a longa peruca cacheada; o seio farto, que não disfarça seu caráter de prótese. Além da pin-up, Morimura demonstra o próprio interesse pela atriz Monroe, de quem seleciona algumas imagens emblemáticas: o fotograma publicitário de Torrentes de paixão e a cena do
43. Cf. Kalliopi Minioudak (2010, p. 116-118). Obra disponível em <www.tate. org.uk/art/artworks/botythe-only-blonde-in-theworld-t0749>.

44. Cf. Romano Giachetti (1976, p. 45). Obra disponível em <www. moma.org/collection//// b r o w s e r e s u 1 t s. php?objectid=79779>.

45. Ver Alberto Boato (1983, p. 109-110; 118). Obra disponível em <artist. christies.com/GeorgeSegal-43869.aspx>.

46. Obra disponível em <www.wikiart.org/.../ rosalyn-drexler-marilynpursued-by-death-1967>.

47. Obra disponível em <www.wikiart.org/en/ salvador-dali-marilynmonroe> 
48. Cf. Dominique Baqué (2002, p. 118-119). As fotografias de Morimura estão disponíveis em <www. luhringaugustine.com/.../ yasumasa-morimura $>$ $;<$ www.saatchigallery. com/.../yasumasa_morimura.htm $>;<$ www.artnet.com/ artists/yas u mas a - morimura $>$; $<$ w w w brooklynmuseumofart/Self-portrait/Actress/WhiteMarilyn1996>.

49. Marco Livingstone (2003, p. 233). Uma das obras da série pode ser vista disponível em <www.warholstars.org/andywarhol/ interview/mark/mark2. html>. respiradouro do metrô de $O$ pecado mora ao lado. A recriação do fotograma mostra um Morimura pesadamente maquiado, imitando cuidadosamente a imagem da diva hollywoodiana, a não ser por um detalhe: um esgar em lugar do sorriso. A primeira encenação colorida (Autorretrato como Marilyn Monroe, 1995) é seguida por uma versão em preto e branco (Autorretrato. D'après Marilyn Monroe, 1996) e por outra com a mesma escala cromática (Autorretrato n. 56. D'après Marilyn Monroe, 1996), tributária do corte feito por Warhol na fotografia de 1953. A intenção de imitar os aspectos mais fascinantes do feminino por meio de fotografias cosméticas alcança o apogeu em Imitando Marilyn Monroe (1 996) e Autorretrato (Atriz). Marilyn preta (1996). Se na primeira obra o efeito kitsch é abrandado pela luz suave que banha a composição em que o artista, posicionado sobre pedestais, assume três poses sensuais com o vestido esvoaçante, na segunda o grotesco é o elemento dominante. $\bigcirc$ erotismo singelo da cena do respiradouro do metrô cede lugar a uma degradação explícita de seu significado: o vestido levantado dá a ver uma penugem e um falo ereto, evidentemente artificiais. A ideia de "beleza decaída", proposta por Dominique Baqué para a série de autorretratos inspirados em atrizes (1994-1996), aplica-se particularmente à Marilyn preta, marcada "pela impossível coincidência entre o corpo inicialmente masculino e o corpo feminino sonhado, e pelo implacável afastamento dos gloriosos ícones do cinema americano" 48

A série "Suvenires pós-Warhol" (1987-1988)49, de Mark Lancaster, é um comentário irônico sobre os métodos de trabalho de Warhol, de quem Lancaster fora assistente em 1964, tendo como elemento deflagrador a morte do artista em 1987. Depois de apropriar-se da capa do catálogo da exposição realizada por Warhol na Tate Gallery em 1971, que reproduzia uma das variações do retrato de Monroe, datada de 1964, Lancaster submete a efígie da atriz a um processo de metamorfose, ao lançar mão de sobreposições e de várias modalidades de transformação. Monroe assume, assim, outras identidades: é associada a figuras das histórias em quadrinhos; remete a obras de Warhol, fundindo-se com a imagem de Liz Taylor (1963) e com o autorretrato do artista datado de 1966, sendo meio apagada por desenhos de sapatos femininos e pelas Flores de 1964, sendo justaposta ao papel de parede Vaca (1966); é transformada em Mona Lisa (1 5031506), no Retrato da senhora Matisse (1905), na Mulher chorando (1937), de Pablo Picasso, entre outros.

\section{Marilyn por Andy Warhol}

A dessublimação de Lancaster leva a indagar se ele não teria encontrado na visão da atriz elaborada por Warhol um motivo ponderável para sua apresentação irreverente do mito de Marilyn Monroe. Ao optar pela representação da atriz em múltiplos retratos, Warhol vale-se de uma imagem do início da carreira: 
o retrato feito por Powolny para divulgar Torrentes de paixão ${ }^{50}$. $\bigcirc$ confronto entre a fotografia original e a apropriação feita por Warhol demonstra que este pretendia retirar a imagem do fluxo temporal, mantendo o rosto como referência quase única. Isolada ou multiplicada, a efígie da atriz é tema de inúmeras obras do artista, e entre elas será destacado, em primeiro lugar, o Díptico de Marilyn (1962)51, por constituir uma das abordagens mais instigantes.

Constituído de cinquenta repetições nem sempre idênticas da imagem feita nos estúdios da 20th Century Fox, Díptico de Marilyn é um retrato múltiplo. Dividida em duas partes - uma colorida, outra em preto e branco -, a obra pode ser considerada uma reflexão sobre as modalidades de construção da imagem da estrela. Atuando na contramão da idealização desse tipo de imagem, o artista propõe uma configuração não apenas artificial, mas também póstuma, visto interessar-se por ela pouco depois de sua morte. $\bigcirc$ exagero é a marca distintiva do trabalho. Na metade colorida, o cabelo apresenta-se como uma massa compacta; a sombra em cima dos olhos adquire um tom extravagante; o vermelho dos lábios é acentuado e, em vários momentos, extravasa da linha de contorno, produzindo um efeito de dissolução. Na porção em preto e branco, a imagem nem sempre é nítida: a insistência numa tintagem escura e o uso de algumas dissolvências, que evocam o fade out cinematográfico, conferem a essa metade do díptico um efeito fantasmagórico, analisado agudamente por Arthur Danto. Na visão deste, Warhol estaria propondo "uma representação gráfica de Marilyn morrendo, sem que o sorriso deixe o seu rosto" 52 . Thomas Crow também propõe um paralelo com o cinema, pois acredita que o artista estaria mobilizando as memórias mais duradouras da atriz, associadas ao preto e branco de películas como $O$ pecado mora ao lado, Quanto mais quente melhor e Os desajustados. Monroe seria, assim, mais real no lado do díptico marcado pela inversão da passagem da vida para a morte, estando mais presente no local em que sua imagem não é tão bem fixada ${ }^{53}$.

Matriz constante, a imagem de 1953 é usada pelo artista em outros momentos de sua produção. As intervenções cromáticas extravagantes do álbum de 1967, que põem em xeque o realismo da fotografia, aludindo ambiguamente a uma dimensão mítica, serão levadas a uma radicalização extrema numa série realizada entre 1979 e 198654. Nela, Warhol realiza uma alteração profunda na imagem tomada de empréstimo em 1962 graças a uma série de operações: explora a ideia do negativo fotográfico, subverte a nitidez da representação, decompõe os contornos do rosto com pinceladas vigorosas, acentua a extravagância cromática, transforma a efígie da atriz numa máscara mortuária grotesca e efêmera. Na série intitulada Marilyn, não há mais um retrato, mas, antes, um antirretrato, em cuja construção o registro fotográfico não é mais tão determinante. Poder-se-ia pensar numa radicalização de $\bigcirc$ retrato de Dorian Gray (1891), na medida em que o artista anula a dicotomia entre o eu (social) e o "antieu" (íntimo), que caracterizava o romance de Oscar Wilde. O que se impõe na série é justamente
50. A atribuição da foto a Powolny é controversa. No site <marilynonline.org/ gallery/thumbnails-php? album $>$, a imagem, acompanhada de outras duas em que a atriz está usando o mesmo vestido, é atribuída a Gene Kornman, que também era fotógrafo da $20^{\text {th }}$ Century Fox.

51. Obra disponível em <www.tate.org/uk/art/ artworks/warhol-marilyndiptych-t03093>.

52. Cf. Arthur Danto (2009, p. 41).

53. Ver Thomas Crow (2001, p. 53).

54. Na exposição $A$ sedução de Marilyn Monroe, uma obra da série é apresentada junto com as versões datadas de 1967 , demonstrando que o curador não se deu conta das diferenças de registro e de concepção. 
55. Ver Annateresa Fabris (2009, p. 145-146).

56. Ver Edgar Morin (2007, p. 159).

57. Ver Andy Warhol (2011, p. 28-30).

58. Obra disponível em $<$ www.moma.org/momalearning/andy-warhol-goldmarilyn-monroe-1962>.

59. Cf. Alex Mitrani (1997, p. 66).

60. Cf. Klaus Honnef (2004, p. 84).

61. Ver Pavel Aleksandrovic Florenskij (1977, pp. 63, 69, 93, 105-106, 137, 144, 152) e Alain Besançon (1997, p. 219-221). o "antieu", o que permite a Warhol dissolver o conceito de ícone perfeito a fim de trazer à tona uma profundidade complexa que aponta para além dela ${ }^{55}$.

As duas possibilidades de representação ensaiadas por Warhol em 1962 e em 1979-1 986 respondem a duas visões de Marilyn Monroe, que podem ser analisadas a partir das considerações de Morin. A primeira é a celebração ambígua do símbolo sexual, da pin-up que se transformou em estrela; a segunda remete ao lado obscuro do mito da imortalidade. $\bigcirc$ rosto da atriz em decomposição rememora uma série de questões enraizadas na ideia de um "duplo trágico": estrela $X$ pessoa de aspirações simples; sucesso e amores $X$ experiências tristes vividas na infância e na adolescência; mulher amada $X$ mulher mal-amada; glória $X$ solidão; vazio X intensidade; infelicidade X existência "maquiada"; aspirações irrealizadas... ${ }^{56}$. Warhol interessa-se pela persona e não pela pessoa que serve de base ao mito porque tem uma percepção clara de como os meios de comunicação de massa constroem as figuras de astros e estrelas. No livro fotográfico América (1985), usa o termo "meias pessoas" para definir as personalidades públicas. $\bigcirc$ conceito tem sua razão de ser, pois o artista contrapõe a imagem pública de tais personalidades, em geral idealizada e destituída de conflitos, à "vida real", ao custo do sucesso e à existência de problemas íntimos, entre outros ${ }^{57}$. Outra obra alicerçada na fotografia de 1953 - Marilyn dourada $(1962)^{58}$ - é produto da percepção de que a civilização contemporânea não comporta "uma reinterpretação religiosa da imagem" 59 , mas isso não impediu que alguns críticos a interpretassem como um ícone. É o caso de Klaus Honnef, para quem Warhol idolatriza a atriz, ao colocar "o desinteressante retrato fotográfico com o sorriso forçado, estereotipado, num amplo espaço que o cerca como uma moldura que dignifica, e ao cobrir todo o campo de dourado - a cor de Jerusalém Celeste, que dá aos ícones um efeito sobrenatural". A matriz "desinteressante" transforma-se profundamente graças ao tratamento que o artista lhe dá: "Os lábios arqueados, os olhos, o cabelo encaracolado e a cara, que perderam o seu volume e realismo graças à técnica da serigrafia, demarcam-se do fundo e flutuam sobre ele tal como estrelas num céu dourado" 60 . Se é evidente que o artista se inspira na estrutura do ícone religioso, é necessário analisar de que maneira ele utiliza as ideias de arquétipo, luz e rosto, centrais na elaboração desse tipo de imagem. $\bigcirc$ arquétipo como visão espiritual é substituído por uma figura mundana, por um ícone criado pelos meios de comunicação de massa. A luz enquanto representação da manifestação divina metaforizada pelo ouro cede lugar a uma imagem mecânica, cuja origem luminosa nada tem a ver com o espírito e com a revelação do invisível e do indizível. O rosto, centro espiritual do ícone por revelar a presença divina ${ }^{61}$, não passa de uma mera superfície, cuja função é apresentar a estrela como um artigo de consumo entre outros.

Ao secularizar a espiritualidade do ícone, ou seja, ao despojátlo da dimensão sagrada para inseri-lo no campo da comunicação de massa, Warhol nada mais faz do que localizar nesta a fonte de uma nova religião com seus ritos e suas figuras de culto. Produz, desse modo, um "icone blasfemo", congenial aos 
mecanismos do star-system, criador de uma "mercadoria total", destinada a um consumo indiferenciado e alicerçada num mecanismo de multiplicação de imagens, que a torna mais desejável e incrementa seu valor. Mercadoria em série, objeto de luxo e fonte de valor, a estrela é como o ouro, "matéria a tal ponto preciosa que se confunde com a própria noção de capital, com a própria noção de luxo (joia), conferindo um valor à moeda fiduciária"62. O ouro, evocado por Morin, permite conferir um significado mundano à obra de Warhol, o qual lança mão da estrutura tradicional do ícone para remeter a efígie da estrela a um universo preciso, interessado em converter a mercadoria em lucro.

A fotografia é um dispositivo fundamental nesse universo, iá que ajuda a configurar a imagem da estrela-mercadoria. Tal problemática é quase sempre o eixo central da maior parte das representações visuais de Monroe propostas pelos artistas plásticos, às quais pode ser acrescentada uma obra que dialoga diretamente com o ícone secular de Warhol. Em The same to you (2003), Celina Yamauchi apropria-se de maneira peculiar da obra deste. Pondo em cena um ato de recepção marcado pela projeção e pelo confronto, a artista brasileira cria uma imagem ambígua, em que espectadora e obra dão a impressão de olhar-se mutuamente. Se a mulher comum que está olhando para o quadro de Warhol pode parecer aspirar ao estatuto estelar de Monroe, há outro movimento igualmente importante na fotografia de Yamauchi: o confronto entre vida e morte. A mulher de carne e osso não é perfeita como o ícone cinematográfico, mas tem uma vantagem: está viva e sua forma não perfeita poderia ser uma maneira de aludir ao que aconteceria com a Monroe real com o passar do tempo. Afinal, quem enuncia a frase escrita logo acima do quadro? Desse modo, Yamauchi, mesmo usando o suporte fotográfico, diferencia-se dos fotógrafos, geralmente empenhados na construção do mito de uma mulher total e multidimensional - deusa das telas e moça simples, da qual irradiam sexo e alma ${ }^{63}$-, alinhando-se com a visão crítica dos artistas plásticos.

À guisa de conclusão

Filtrada e idealizada pelo star-system e pelos meios de comunicação de massa, a vida da atriz sofre um processo de espiritualização, seja com a revelação de seus gostos literários, seja depois do casamento com o dramaturgo Arthur Miller (1956). A fotografia é, mais uma vez, um elemento determinante nesse processo, como provam as inúmeras imagens dedicadas a astros e estrelas no exercício de atividades elevadas: pintando, consultando um livro, falando dos próprios interesses culturais ${ }^{64}$. Monroe inscreve-se, sem problemas, nessa construção idealizada. Sem abdicar do papel de deusa das telas, dá mostras de ser portadora de uma alma sensível, ao deixar-se fotografar entretida na leitura de Heinrich Heine, James Joyce, Michael Chekhov, Walt Whitman, Arthur Miller, segurando uma publicação sobre
62. Cf. Edgar Morin (2007, p. 100-101).

63. Ver Edgar Morin (2007, p. 32-33).

64. Ver Edgar Morin (2007, pp. 32, 46). 
65. Essas imagens estão reproduzidas no livro organizado por Bernard Comment e Stanley Buchthal (2011).

66. Ver Elio Grazioli (2001, p. 155).

67. O uso de imagens da atriz nos filmes La rabbia (A raiva, 1963), de Pier Paolo Pasolini, e La société $d u$ spectacle (A sociedade do espetáculo, 1973), de Guy Debord, demonstra que esta pode ser fonte de leituras diferenciadas, apesar da semelhança metodológica entre as duas operações, que envolve o uso de materiais de arquivo e de textos. Dividido em duas partes, uma confiada a Pasolini, outra a Giovannino Guareschi, La rabbia é uma reflexão sobre o momento contemporâneo. A sequência dedicada a Monroe insere-se num contexto amplo no qual Pasolini faz referência à revolução ocorrida na Hungria em 1955, à luta de Fidel Castro em Cuba (19521959), ao processo de descolonização, à luta de classe, ao desaparecimento do universo camponês, à industrialização, ao conservadorismo, ao anticomunismo e à burguesia. Dentro desse panorama, a atriz desempenha o papel de paradigma da morte da beleza, além de adquirir uma nova configuração mítica, baseada na analogia biográfica entre sua vida e a de Cristo. Debord, por sua vez, constrói La société du spectacle com imagens do assassinato de Lee Harvey Oswald (24 nov. 1963), da Guerra Civil Espanhola (1936-1939), da revolução húngara, de maio de 1968 , entre outras, e com textos extraídos do próprio livro (1967), de comunicados do Comitê de Ocupação da Sorbonne (1968) e de obras de Niccolò Machiavelli, Karl Marx, Charles-Alexis de Tocqueville, Émile Pouget e
Goya, folheando um livro numa livraria, contemplando uma escultura de Edgar Degas, frequentando escritores e poetas como Karen Blixen, Carson McCullers, Edith Sitwell, Carl Sandburg, escrevendo... A evidência da pose, a combinação numa mesma imagem da sedutora e da moça comum, as datas em que as fotografias foram feitas - entre 1951 e 1962 - não deixam dúvidas sobre a participação ativa da atriz na construção dessa imagem idealo5.

Os artistas plásticos, ao contrário dos fotógrafos, interessam-se quase sempre pela desmontagem do mito, pela acentuação de seu caráter construído, pela avaliação crítica do star-system com suas imagens ora grotescas, ora realistas, mas impregnadas por um viés corrosivo que contesta ou até mesmo destrói as idealizações fotográficas. $\bigcirc$ título italiano de $\bigcirc$ rio das almas perdidas, Magnifica preda, isto é, "magnífica presa", parece aplicar-se à perfeição à construção da imagem de Monroe pela indústria cultural. A superfície unitária da fotografia é posta em xeque na décollage de Rotella, que demonstra um comportamento ambíguo para com a figura da diva cinematográfica, cujo corpo funciona como uma metáfora da imagem e da publicidade. $\bigcirc$ cartaz rasgado dá a ver gestos reais (rancor, sadismo, fascínio); seu significado de amor e ódio remete tanto ao objeto em si quanto à imagem representada ${ }^{66}$.

"Magnífica presa" dos meios de comunicação de massa, mas consciente do que estava sendo feito com sua imagem, a figura de Marilyn Monroe propiciou duas operações visuais fundamentais: o mito imorredouro criado pela fotografia e pelo cinema ${ }^{67}$ e a memória crítica forjada pelas artes plásticas. "Ícone como o rosto da Mona Lisa, atrás do qual não se sabe o que há" 68 , a atriz continua a habitar o imaginário contemporâneo, numa demonstração de que a construção mítica não pode prescindir da visão crítica, sob pena de mutilar a história e de privá-la de alguns de seus indispensáveis instrumentos analíticos.

\section{REFERÊNCIAS}

A sociedade do espetáculo (manuscrito do filme de Debord). Disponível em: <http://www. reocities.com/projetoperiferia4/sefilme.htm>. Acesso em: 20 ago. 2012.

ALLOWAY, Lawrence. Popular Culture and Pop Art. In: FRANCIS, Mark. (Org.). Pop. Londres: Phaidon Press, 2005, p. 241-243.

BAQUÉ, Dominique. Mauvais genre(s): érotisme, pornographie, art contemporain. Paris: Éditions du Regard, 2002.

BESANÇON, Alain. A imagem proibida: uma história intelectual da iconoclastia. Tradução por Carlos Sussekind. Rio de Janeiro: Bertrand Brasil, 1997.

BOATTO, Alberto. Pop art. Roma-Bari: Laterza, 1983. 
BUCHTHAL, Stanley; COMMENT, Bernard. (Org.). Fragmentos: poemas, anotações íntimas e cartas de Marilyn Monroe. Tradução por Renato Rezende, Aline Tenório Cordeiro e Marcelo Rede. São Paulo: Tordesilhas, 2011.

COKE, Van Deren. The Painter and the Photograph: from Delacroix to Warhol. Albuquerque: University of New Mexico Press, 1972.

CROW, Thomas. Saturday Disasters: Trace and Reference in Early Warhol. In: MICHELSON, Annette. (Org.). Andy Warhol. Cambridge/Londres: The MIT Press, 2001, p. 49-66.

DANTO, Arthur Coleman. Andy Warhol. New Haven/Londres: Yale University Press, 2009.

DEBORD, Guy. La sociedad del espectáculo. Buenos Aires: La Marca, 1995.

FABRIS, Annateresa. “A 'pós-imagem mecanizada': fotografia e arte pop”. In: arredores. Florianópolis: Letras Contemporâneas, 2009, p. 142-148, 304-305. .Fotografia e

FLORENSKIJ, Pavel. Le porte regali: saggio sull'icona. Milão: Adelphi, 1977.

GIACHETTI, Romano. Porno-power: pornografía y sociedad capitalista. Barcelona: Editorial Fontanella, 1976.

Golden Dreams and New Wrinkle. Marilyn Monroe Nude. Disponível em: <www.marilynmonroe. com/camera/calendar>. Acesso em: 20 mar. 2015.

GRAZIOLI, Elio. Arte e pubblicità. Milão: Bruno Mondadori, 2001.

GUBERN, Román. Mensajes icónicos en la cultura de masas. Barcelona: Editorial Lumen, 1974.

HONNEF, Klaus. Pop Art. Colônia-Londres-Los Angeles-Madri-Paris-Tóquio: Taschen, 2004.

KOETZLE, Hans-Michael. Photoicons: the Story Behind the Pictures. Hong Kong: Taschen, 2005.

La rabbia. Direção: Pier Paolo Pasolini; Giovannino Guareschi. Itália. 1963. (51 min) Disponível em: <https://it.wikipedia.org/wiki/La_rabbia_(film_1963)>. Acesso em: 20 ago. 2012.

La Société du Spectacle. Guy Debord. França: Simar, 1973. (88 min). Disponível em: <www.ubu. com/film/debord_spectacle.html>. Acesso em: 20 ago. 2012.

LIVINGSTONE, Marco. Pop Art: a Continuing History. Londres: Thames \& Hudson, 2003.

MEKAS, Jonas. Movie-journal (1959-65). In: FRANCIS, Mark. (Org.). Pop. Londres: Phaidon Press, 2005, p. 246-248.

MINIOUDAKI, Kalliopi. Pop Proto-feminism: Beyond the Paradox of the Woman Pop Artist. In: SACHS, Sid; MINIOUDAKI, Kalliopi. (Org.). Seductive subversion: women pop artists, 1958-1968. Philadelphia: University of the Arts; Nova York/Londres: Abbeville Press, 2010, p. 90-143.

MITRANI, Alex. Warhol y Ritchter: el milagro figurado. Lápiz, Madri, n. 138, p. 60-67, dec. 1997.

MORIN, Edgar. Les stars. Paris: Seuil, 2007.
Vladimir Soloviev. Marilyn Monroe é evocada no segmento dedicado à estrela, cujo texto é derivado do livro que deu origem à película. A construção da sequência é bem interessante: imagens de Johnny Halliday, dos Beatles, de Eddy Mitchell e Dick Rivers antecedem a evocação da atriz. Cenas com Monroe voltam a ser apresentadas depois da figura de François Mitterand, de maneira a confirmar a tese do autor sobre a existência de pseudoastros na esfera do poder estatal e de astros do consumo dotados de um pseudopoder sobre o vivido. Pura imagem, destituída de existência real. Monroe configura-se como a encarnação da verdade do espetáculo. Com essa articulação, Debord destaca o aspecto "industrial" e descartável das figuras do astro e da estrela: trata-se de formas que só adquirem sentido dentro da linguagem especializada do espetáculo. Cf. Gabriel Ferreira Zacarias (2012); La rabbia (1963, 51 min) - Disponível em: <https://it.wikipedia.org/ wi ki / L a _ r a bi a (film_1963)>; Guy Debord - Society of-Ubu Web, s. d.; A sociedade do espetáculo (manuscrito do filme de Debord), s.d.; Guy Debord (1995, p. 60). Agradeço a Mariarosaria Fabris a indicação do artigo de Gabriel Ferreira Zacarias.

68. Ver Antonio Tabucchi (2011, p. 18). 
Pin-up. Disponível em: < https://pt.wikipedia.org/wiki/Pin-up >. Acesso em: 02 jan. 2015.

Pin-up girl. Disponível em: < https://en.wikipedia.org/wiki/Pin-up_girl >. Acesso em: 02 jan. 2015.

PRECIADO, Beatriz. Pornotopía: arquitectura y sexualidad en "Playboy" durante la guerra fría. Barcelona: Anagrama, 2010.

TABUCCHI, Antonio. O pó da borboleta. In: BUCHTHAL, Stanley; COMMENT, Bernard. (Org.). Fragmentos: poemas, anotações íntimas e cartas de Marilyn Monroe. Tradução por Eugênio Vinci de Moraes. São Paulo: Tordesilhas, 2011, p. 11-18.

The Pinup Files. Disponível em: <www.thepinupfiles.com/moran.html>. Acesso em: 20 mar. 2015.

VETTESE, Angela. Rotella e il cinema. Milão: Skira, 2012.

WARHOL, Andy. America. Londres: Penguin, 2011.

ZACARIAS, Gabriel Ferreira. La vedette, "representation spectaculaire de l'homme vivant". Ad hoc, Rennes, n. 1, 02 jul. 2012. Disponível em: < http://www.cellam.fr/wp-content/uploads/2012/07/ Rzacarias-ad-hoc-2.pdf > Acesso em: 20 ago. 2012.

Artigo apresentado em 21/03/2015. Aprovado em 17/04/2015. 